\title{
Palavra de artista ou como decifrar uma obra surrealista*
}

Márcia Arbex**

RESUMO: Tradução do texto Qu'est-ce que le surréalisme?, de Max Ernst, precedida de apresentação crítica.

O texto que ora trazemos ao conhecimento do público, através da tradução para o português, constitui a introdução do catálogo da exposição coletiva surrealista, realizada na Kunsthaus, em Zurique, em 1934. Sua originalidade repousa na sua autoria: coube ao artistapoeta Max Ernst, que também participou da exposição, a redação do texto.'

O título é revelador: o texto apresenta-se como resposta à pergunta tantas vezes formulada - o que é o surrealismo? Seu objetivo é transparente e explícito: "Minha breve apresentação destina-se unicamente a desfazer, de certa forma, a confusão das idéias sobre o surrealismo, confusão esta que se expande e já se introduziu fortemente em uma parte da opinião pública." Destinado a esclarecer o público, o breve texto de Max Ernst visa ainda instruir o leitor do

\footnotetext{
* Recebido para publicação em junho de 2000.

**Professora do Departamento de Letras Românicas da Faculdade de Letras da UFMG.

'Este trabalho faz parte de un projeto de pesquisá em curso, cujo objetivo é constituir un corpus de textos escritos por artistas plásticos pertencentes aos movimentos dadaista e surrealista, e traduzi-los para o português.
} 
catálogo e o visitante da exposição, ajudando-os na "compreensão" das obras ali apresentadas. Ernst retoma alguns dos princípios capitais do movimento, sobretudo aqueles que dizem respeito à definição de uma "pintura surrealista", e revela, desta forma, uma certa fragilidade e instabilidade do movimento diante de um público que, dez anos após a publicação do primeiro Manifesto do surrealismo (1924), de André Breton, parece não ter compreendido, ainda, o alcance da poética e da estética surrealistas.

Tal instabilidade é compreensível pois, no início, o surrealismo não se parece em nada com uma escola literária. Por um lado, os surrealistas propõem uma reforma profunda da linguagem poética. Louis Aragon, por exemplo, fiel ao programa inicial do grupo, afirma que não há poesia sem meditação sobre a linguagem e, a cada passo, reinvenção da linguagem, o que significa romper com as normas gramaticais e as leis do discurso (ARAGON, 1942:14). Por outro lado, o movimento reivindica técnicas que não possuem nenhum reconhecimento literário: a escrita automática, o sono hipnótico, os textos coletivos e as colagens, que surgem como interrogações do hasard objectif (acaso objetivo). As primeiras pinturas que reinvidicam a apelação de "surrealista" tampouco respondem aos padrões vigentes; ao contrário, as exposições causam surpresa, indignação ou provocam escândalos.

No primeiro Manifesto do surrealismo (1924), notamos que seu autor, André Breton, trata essencialmente de questões de ordem poética, não considerando até então a possibilidade de pensar em uma estética surrealista; ele hesita em estender a noção de surrealismo à arte: alguns pintores, indiferentemente, são citados em uma nota de rodapé. ${ }^{2}$ Uma discussão sobre a possibilidade da existência de uma pintura surrealista, isto é, de uma pintura que escapasse aos mecanis- 
mos intelectuais de controle, à lógica e à razão, desenvolveu-se no interior do grupo e surgiu nos primeiros números de La Révolution surréaliste. $^{3}$

Segundo Philippe Soupault, entretanto, desde 1921, com a chegada das colagens de Max Ernst em Paris para uma exposição organizada pelos surrealistas (Exposition Dada Max Ernst), ele e Breton começaram a acreditar que o surrealismo poderia "exercer seu papel e estender sua influência ao domínio das artes plásticas"'(SOUPAULT: 1989), pois em tais colagens "se traduz uma proposta de organização visual inteiramente virgem, mas que corresponde ao que Lautréamont e Rimbaud buscavam na poesia” (BRETON, 1965:64). Breton e Soupault dizem ter compreendido que o pintor poderia obter, no domínio plástico, a "liberação" que os escritores buscavam na poesia; dizem ainda ter encontrado nessas colagens o "estado de espírito" e o "clima" presentes em Les Champs Magnétiques (Os campos magnéticos, 1919) (SOUPAULT: ibid.), texto poético redigido sob a influência da técnica da "narrativa automática" descrita por Freud. As colagens proporcionavam, de fato, uma amostra das possibilidades de se estender as pesquisas poéticas ao domínio das artes plásticas (dando, ao mesmo tempo, um equivalente visual que confirmava a validade das imagens verbais dos textos automáticos). Todavia, André Breton não menciona a importância dessas colagens para a definição de uma "arte surrealista", no Manifesto de 1924.

Somente a primeira manifestação coletiva do surrealismo no domínio das artes plásticas, a exposição La Peinture surréaliste (Galerie Pierre, Paris, 1925) viria responder positivamente às questões levantadas nos debates sobre a existência de tal pintura. $\mathrm{O}$ prefácio do catálogo desta primeira exposição, escrito por Breton e Robert Desnos, é pouco informativo mas poeticamente trabalhado: a partir dos títulos das obras expostas, os autores compuseram uma paisagem 
imaginária onde personagens e coisas se deslocam e se unem misteriosamente.

O texto $O$ que é o surrealismo?, contrariamente ao que acaba de ser citado, é bem mais informativo e aborda quatro aspectos essenciais do movimento: o mito do "autor", o procedimento da escrita automática na arte, a questão da imagem surrealista e a definição da surrealidade.

Interessa-nos destacar, sobretudo, as relações que o autor procura estabelecer entre a poesia e a pintura, dando um suporte teórico à defesa da arte surrealista. Para tanto, Max Ernst retoma a questão da escrita automática e da imagem surrealista, abordadas amplamente no Manifesto do surrealismo, e ao qual o autor remete no fim de seu texto.

Max Ernst afirma que escultores e pintores buscavam um procedimento análogo à escrita automática para atingir a objetividade poética, isto é, proscrever a razão, o gosto e a vontade consciente, do processo de elaboração da obra de arte; e que somente os resultados da prática, e não da teoria, poderiam ajudá-los. Seu objetivo é produzir a "étincelle", como diz Breton em Les Pas perdus (1924) (BRETON, 1988:246), produzir uma deflagração poética através das imagens visuais, assim como os poetas através das imagens verbais dos textos automáticos.

As colagens do próprio Ernst apresentam características do que seria a imagem poética surrealista, obtida através de um procedimento automático. Pierre Reverdy, ao qual Breton recorre no Manifesto de 1924, observa o caráter involuntário da imagem - "criação pura do espírito" - e situa sua origem na "aproximação de duas realidades mais ou menos distanciadas" (retomando a famosa frase de Lautréamont). Esta aproximação deveria produzir um efeito de contradição, onde analogias pouco comuns, novas e surpreendentes se estabeleceriam no interior da imagem, aspecto que constitui uma característica das colagens. Em 1925, com a descoberta do frottage ("esfrega": técnica que consiste em colocar uma folha de papel sobre 
uma superfície áspera ou em relevo, e esfregar com um lápis o outro lado da folha para obter efeitos inesperados), Max Ernst oferece um segundo procedimento equivalente à escrita automática:

O recurso do frottage, por se basear unicamente na intensificação da irritabilidade das faculdades do espírito através de técnicas apropriadas, que excluem qualquer condução mental consciente (de razão, de gosto, de moral), reduzindo ao extremo a parte ativa daquele que, até aquele momento, chamávamos de autor da obra, esse recurso revelou-se em seguida o verdadeiro equivalente do que já era conhecido pelo termo de escrita automática. (ERNST, 1936:244)

Salvador Dalí, por sua vez, seguirá o caminho da pintura em trompe-l' 'il com a fixação de imagens oníricas, através do "método da paranóia crítica" criado por ele. Trata-se, segundo o artista, de um método espontâneo de conhecimento irracional, baseado na objetivação crítica e sistemática das associações e interpretações delirantes (apud BIRO, 1982:317).

Max Ernst chama a atenção para não se confundir a pintura surrealista com uma pintura onírica, na qual os artistas se limitariam a copiar seus sonhos (fato que viria a acontecer com Dalí). Deve-se compreender que o artista se move livremente nas fronteiras entre o mundo interior e o exterior; que ele cria, no real, o maravilhoso, podendo, assim, atingir a surrealidade (surréalité), definida como a resolução de dois estados aparentemente contraditórios, o real e o imaginário, unidos em uma forma de realidade absoluta.

Para finalizar, o autor de $O$ que é o surrealismo? justifica a presença das esculturas e objetos na exposição, que passaram a integrar o conjunto das manifestações artísticas surrealistas a partir do início dos anos 30 . O que seria uma escultura surrealista? É possível utilizar um procedimento análogo à escrita automática na execução de objetos tridimensionais? O que é o objeto surrealista? Hans Arp, um dos fundadores de dadá em Zurique, diz utilizar o acaso para compor suas peças, realizadas com materiais desconhecidos, pedaços de madeiras encontrados, que se organizam em um vocabulário de formas elementares, orgânicas. Albert Giacometti, conside- 
rado escultor do invisível e autor do primeiro objeto "com funcionamento simbólico" (L'heure des traces ou La boule suspendue, 1930$31)$, relata que suas esculturas e objetos têm por origem os sonhos e o acaso objetivo:

Há anos tenho realizado unicamente esculturas que se oferecem inteiramente prontas à minha mente; limitei-me a reproduzi-las no espaço sem nada mudar, sem me perguntar o que elas significavam (...). Uma vez o objeto construído, minha tendência é encontrar ali, transformadas e deslocadas, imagens, impressões, fatos que me comoveram profundamente (...), formas que me parecem muito familiares, apesar de eu ser, na maior parte das vezes, incapaz de identificá-las, o que as torna cada vez mais pertubadoras... (Minotaure, $n^{\circ} 3-4,1933$, apud BIRO:182).

Para o terceiro artista citado por Ernst no catálogo, Sálvador Dalí, o objeto surrealista é "um objeto que apresenta um mínimo de funcionamento mecânico... baseado nos fantasmas e representações suscetíveis de serem provocados pela realização de atos inconscientes" (apud BIRO, 1982:306).

Observamos que a criação de objetos surrealistas segue o mesmo procedimento que a poesia ou a pintura: os objetos são "escolhidos" ou oferecidos ao artista através do sonho, do acaso objetivo, das alucinações; em geral, são objetos banais e conhecidos, deslocados de seu contexto e de sua função, e associados a outros objetos, adquirindo, assim, um poder e uma função inéditos. É o encontro celebrado por Lautréamont da máquina de costura e do guarda-chuva. São chamados de objetos com "funcionamento simbólico" porque revelam, por trás de seu aspecto manifesto, impulsos e sensações até então desconhecidos.

O autor do texto $O$ que é o surrealismo? parece ter percebido a importância de se impor a arte surrealista, apresentando aos leitores do catálogo e aos visitantes da exposição, certos "códigos" específicos e necessários para o deciframento das imagens e objetos surrealistas. Seu trabalho, decerto, não foi em vão. Se, durante muito tempo, alguns dos próprios surrealistas duvidaram da capacidade das artes plásticas de veicularem os princípios do movimento, há de se reco- 
nhecer, com José Pierre (1991:81), que a arte surrealista - com suas pinturas, objetos, esculturas, facilitou consideravelmente a difusão do movimento no mundo, muito mais até que seus textos teóricos ou poéticos.

RÉSUMÉ: Traduction du texte Qu'est-ce que le surréalisme?, de Max Ernst, accompagneé d'une introductin critique.

\section{Bibliografia}

ARAGON, Louis. Les Yelx d'Elsa. Paris: Seghers, 1942.

BIRO, Adam, PASSERON, René. Dictionnaire Général du Surréalisme et de ses environs. Paris: Puf, 1982.

BRETON, André. Le surréalisme et la peinture (1928). Paris: Gallimard, 1965.

BRETON, André. Manifeste du Surréalisme (1924), Euvres complètes I. Paris: Gallimard, 1988. (Bibliothèque de la Pléiade)

ERNST, Max. Au delà de la peinture (1936). Écritures. Paris: Gallimard, 1970.

ERNST, Max. Qu'est-ce que le surréalisme? (1934). Écritures. Paris: Gallimard, 1970. SOUPAULT, Philippe. Les surréalistes, même. France Culture, agosto de 1989.

PIERRE, José. Surrealismo e artes plásticas. O Surrealismo/ organização de R. PONGE. Porto Alegre: Ed. da Universidade, UFRGS, 1991. 


\section{O que é o surrealismo?}

A palavra delito não foi, em geral, compreendida.

Paul Éluard

Persistia no mundo da cultura ocidental como última superstição, como um triste resíduo do mito da criação, a lenda do poder criador do artista. Um dos primeiros atos revolucionários do surrealismo foi o ataque a este mito por meios objetivos, da forma a mais corrosiva e, com certeza, destruindo-o para sempre. Ao mesmo tempo, o surrealismo insistia energicamente no papel puramente passivo do "autor" no mecanismo da inspiração poética e denunciava, como contrário a esta, qualquer controle "ativo" da razão, da moral e qualquer consideração estética. O autor pode assistir como espectador ao nascimento da obra e seguir as fases de sua evolução com indiferença ou paixão. Da mesma forma que o poeta espreita o desenrolar automático de seu pensamento anotando todos seus incidentes, o pintor joga sobre o papel ou sobre a tela aquilo que sua inspiração visual lhe sugere. É o fim, nem precisa dizê-lo, da velha noção de "talento", o fim da divinização do herói, da fábula agradável aos lúbricos da admiração em que se elogia a fecundidade do artista que põe três ovos hoje, dois amanhã e nenhum no domingo. Como todo homem "normal" (e não só o "artista") carrega consigo, como se sabe, uma reserva inesgotável de imagens enterradas no seu subconsciente, trata-se de uma questão de coragem ou então de utilização do mecanismo de liberação (tal a "escrita automática") revelar, através da exploração do inconsciente, achados não falsificados, "imagens" que não se descoloriram sob o controle da razão, e cujo encadeamento pode ser qualificado de conhecimento irracional ou objetividade poética, segundo a definição de Paul Éluard : "A objetividade poética só 
existe na sucessão, no encadeamento de todos os elementos subjetivos do qual o poeta é, até nova ordem, não o mestre mas o escravo." Donde concluímos que o "artista" falsifica.

No ínicio, os pintores e os escultores não acharam fácil encontrar um procedimento análogo à "escrita automática" e que fosse adaptado às suas possibilidades técnicas de expressão, a fim de chegar à objetividade poética, isto é, proscrever do processo de elaboração da obra de arte a razão, o gosto e a vontade consciente. Nenhuma reflexão teórica poderia socorrê-los. Ao contrário, somente tentativas práticas e seus resultados poderiam ajudá-los. "O encontro ocasional sobre uma mesa de dissecação de uma máquina de costura e de um guarda-chuva" (Lautréamont) é, hoje, um exemplo universalmente conhecido, quase clássico, do fenômeno descoberto pelos surrealistas, a saber, que a aproximação de dois (ou mais) elementos de natureza aparentemente oposta sobre um plano de natureza oposta à deles, provoca as mais violentas deflagrações poéticas. Inúmeras experiências individuais ou coletivas (por exemplo, aquelas conhecidas pelo nome de "cadáver delicioso"), demonstraram o partido que podemos tirar deste procedimento. Desta forma, percebemos que quanto mais arbitrário era o encontro dos elementos, mais certamente se produziria - através da centelha de poesia que dali jorraria - uma mudança completa ou parcial no sentido dos objetos. A alegria que se experimenta diante de qualquer metamorfose bem-sucedida, não responde a um miserável desejo estético de distração, mas sim à secular necessidade do intelecto de se liberar do paraíso ilusório e tedioso das lembranças petrificadas, e procurar um novo domínio de experiência incomparavelmente mais vasto, onde as fronteiras entre o mundo interior - como costuma-se chamar - e o mundo exterior (segundo a concepção clássica-filosófica) apagar-se-ão cada vez mais e, com certeza, desaparecerão completamente um dia, quando métodos mais precisos que a escrita automática terão sido encontrados. É neste sentido que, sem qualquer pretensão, chamei de "História natural" um conjunto de estampas sobre as quais havia fixado, com a maior precisão possível, uma série de alucinações visuais. A significação re- 
volucionária desta fisiografia, que sem dúvida produz inicialmente uma impressão de absurdo, ficará talvez mais clara se considerarmos que a microfísica moderna apresentou resultados análogos. Depois de medir um elétron em movimento livre e medir ulteriormente o seu deslocamento, P. Jordan declara: "Mas a distinção entre o mundo interior e o mundo exterior encontra-se privada de uma de suas principais bases com a refutação experimental da idéia que no mundo exterior apresentam-se fatos que, independentemente do processo de observação, possuem uma existência objetiva."

Portanto, quando dizem que os surrealistas são pintores de uma realidade onírica em mudança contínua, isto não quer dizer que eles copiam seus sonhos sobre as telas (seria um naturalismo ingênuo e descritivo) nem tampouco que cada um deles constrói, com os elementos de seu sonho, seu próprio mundinho, para ali se instalar confortavelmente ou exercer sua maldade (seria $A$ fuga para for a do tem$p o^{4}$ ). Ao contrário, isto significa que eles se movem livremente, com ousadia e naturalmente na região fronteiriça entre o mundo interior e o mundo exterior que, apesar de ainda ser imprecisa, possui uma realidade completa ("surrealidade") física e psíquica; que eles tomam nota do que vêem ali e intervêm energicamente onde seus instintos revolucionários o incitam a fazê- $10^{5}$. A oposição fundamental entre meditação e ação (segundo a concepção clássica-filosófica) deixa de existir ao mesmo tempo que a distinção entre mundo exterior e mundo interior. E aí reside a significação universal do Surrealismo, a saber, que nenhum domínio da vida pode fechar-se a ele após esta descoberta. É desta forma que a escultura, que visivelmente mantinha uma atitude de desconfiança em relação a qualquer automatismo, também aproximou-se do Surrealismo. Ao lado das esculturas de Hans Arp e Giacometti apresentadas nesta exposição, mencionaremos os

\footnotetext{
‘Alusão ao livro de Hugo Ball: Die Fluchl alis der Zeil.

${ }^{3} \mathrm{Em}$ oposição ao abstracionismo que, a contrário, limita intencionalmente suas possibilidades às ações reciprocas e puramente estéticas de cores, superficics, volumes, linhas, espaço, etc. Aparentemente com o criaçăo".
} 
objetos surrealistas com "funcionamento simbólico" (por exemplo, A bola suspensa de Giacometti) e os projetos utópicos cuja descrição abaixo pode dar uma idéia ao leitor: "Grandes automóveis, três vezes maiores que o normal, serão reproduzidos (com uma minúcia de detalhes que ultrapassará a das formas mais exatas) em gesso ou em ônix, envolvidos em roupa íntima feminina, e fechados em sepulturas cuja localização só será identificada pela presença de um pequeno relógio de palha." (Salvador Dalí).

Obras plásticas existentes já podem funcionar, na experimentação surrealista, como qualquer outra "realidade", enquanto elementos poéticos, assim como nos mostraram as pesquisas coletivas visando o embelezamento irracional de Paris: "As estátuas mais convencionais embelezariam maravilhosamente os campos. Algumas mulheres nuas, de mármore, fariam muito efeito sobre uma vasta planície cultivada. Animais nos riachos e concílios entre graves personagens engravatados de preto nos rios formariam charmosos escolhos na monotonia do fluxo. As encostas das montanhas se enfeitariam admiravelmente com todas as petrificações da dança. E considerando a mutilação indispensável, quantas cabeças sobre o solo, quantas mãos sobre as árvores, quantos pés sobre o sapé!" (Paul Éluard).

O que é o surrealismo? Se esperarmos uma definição que responda a esta questão, ficaremos decepcionados o tempo que durar esse movimento. Minha breve apresentação destina-se unicamente a desfazer, de certa forma, a confusão das idéias sobre o surrealismo, confusão esta que se expande e já se introduziu fortemente em uma parte da opinião pública. Finalmente, só posso remeter às duas obras de André Breton: Manifestos do surrealismo e Os vasos comunicantes. $\mathrm{Se}$, nas sucessivas iniciativas dos surrealistas foram detectadas contradições que ainda hoje se apresentam, isto indica que o movimento está no caminho certo. Considerando que este movimento perturbou completamente as relações entre as "realidades", ele não poderia deixar de contribuir para a aceleração da crise de consciência generalizada e de conhecimento de si mesmo que se faz sentir atualmente. 


\section{Qu'est-ce que le surréalisme?}

Le mot délit n'a, en général, pas été compris.

Paul Éluard

Il restait au monde de la culture occidentale comme dernière superstition, comme un triste résidu du mythe de la création, la légende du pouvoir créateur de l'artiste. Un des premiers actes révolutionnaires du surréalisme a été d'attaquer ce mythe par des moyens objectifs, sous la forme la plus corrosive et, certainement, de l'avoir détruit à tout jamais. En même temps il insistait avec force sur le rôle purement passif de "I'auteur" dans le mécanisme de l'inspiration poétique et dénonçait, comme contraire à celle-ci, tout contrôle "actif" de la raison, de la morale et toute considération esthétique. L'auteur peut assister en spectateur à la naissance de l'œuvre et poursuivre les phases de son développement avec indifférence ou passion. De même que le poète épie le cours automatique de sa pensée et en note tous les incidents, le peintre jette sur le papier ou sur la toile ce que son inspiration visuelle lui suggère.

C'en est fini, cela va sans dire, de la vieille conception de "talent", fini aussi de la divinisation du héros, de la fable agréable aux lubriques de l'admiration et qui vante la fécondité de l'artiste qui pond trois œufs aujourd'hui, deux demain et rien dimanche. Comme tout homme "normal" (et pas uniquement "l'artiste") porte, on le sait, une réserve inépuisable d'images enfouies dans son subconscient, c'est affaire de courage ou du procédé de libération employé (tel que "l'écriture automatique") de mettre au jour, par des explorations dans l'inconscient, des trouvailles non falsifiées, des "images" qu'un contrôle n'a pas décolorées et dont l'enchaînement peut être qualifié de connaissance irrationnelle ou d'objectivité poétique, suivant la 
définition de Paul Éluard : 'L'objectivité poétique n'existe que dans la succession, dans l'enchaînement de tous les éléments subjectifs dont le poète est, jusqu'à nouvel ordre, non le maître mais l'esclave." D'où il ressort que "l'artiste" falsifie.

Au début, il ne parut pas facile aux peintres et aux sculpteurs de trouver un procédé analogue à "l'écriture automatique" et adapté à leurs possibilités techniques d'expression, afin d'accéder à l'objectivité poétique, c'est-à-dire à proscrire du processus d'élaboration de l'œuvre d'art la raison, le goût et la volonté consciente. Toutes recherches théoriques ne pouvaient, en l'occurrence, leur être d'aucun secours. Seuls, au contraire, des essais pratiques et leur résultat pouvaient les aider. "La rencontre fortuite sur une table de dissection d'une machine à coudre et d'un parapluie" (Lautréamont) est aujourd'hui un exemple universellement connu et devenu presque classique du phénomène découvert par les surréalistes, à savoir que le rapprochement de deux (ou plusieurs) éléments de nature apparemment opposée sur un plan de nature opposée à la leur provoque les plus violentes déflagrations poétiques. D'innombrables expériences individuelles ou collectives (par exemple celles qui sont connues sous le nom de "Cadavre exquis") ont démontré le parti que l'on peut tirer de ce procédé. Ce faisant, on se rendit compte que plus la rencontre des éléments était arbitraire et plus sûrement, par l'étincelle de poésie qui en jaillissait, il devait se produire un changement complet ou partiel du sens des objets. La joie que l'on éprouve à toute métamorphose réussie ne répond pas à un misérable désir esthétique de distraction mais bien au séculaire besoin de l'intellect de se libérer du paradis illusoire et ennuyeux des souvenirs figés, et de rechercher un nouveau domaine d'expérience incomparablement plus vaste où les frontières entre le monde intérieur, comme on est convenu de l'appeler, et le monde extérieur (selon la conception classico-philosophique) s'effaceront de plus en plus et, vraisemblablement, disparaîtront un jour complètement lorsque des méthodes plus précises que l'écriture automatique auront été trouvées. C'est dans ce sens que je pus, sans aucune prétention, qualifier 
d' "Histoire naturelle" une suite de planches sur lesquelles j'avais fixé avec la plus grande précision possible, une série d'hallucionations visuelles. La signification révolutionnaire de cette physiographie, qui sans doute produit d'abord une impression absurde, sera peut-être plus intelligible du fait que la microphysique moderne a donné des résultats analogues. Après mesurage d'un électron en mouvement libre et mesurage ultérieur de son déplacement, P. Jordan déclare : "Mais la distinction entre monde intérieur et monde extérieur se voit privée d'un de ses principaux soutiens avec la réfutation expérimentale de l'idée qu'il se présente dans le monde extérieur des faits qui, indépendamment du processus d'observation, possèdent une existence objective."

Par conséquent, lorsqu'on dit des surréalistes qu'ils sont les peintres d'une réalité onirique en perpétuel changement, il ne faut pas entendre par là qu'ils copient leurs rêves sur leur toile (ce serait du naturalisme naîf et descriptif) ou bien que chacun d'eux se bâtit avec les éléments de son rêve son petit monde à lui, pour y prendre ses aises ou y exercer sa méchanceté (ce serait "La fuite hors du temps"6. Cela signifie au contraire qu'ils se meuvent librement, hardiment et tout naturellement dans la région frontière du monde intérieur et du monde extérieur qui, bien qu'elle soit imprécise encore, possède une complète réalité ("surréalité") physique et psychique ; qu'ils enregistrent ce qu'ils y voient et qu'ils interviennent énergiquement là où leurs instincts révolutionnaires les poussent à le faire $^{7}$. L'opposition fondamentale entre méditation et action (selon la conception classico-philosophique) tombe avec la distinction entre monde extérieur et monde intérieur et c'est là que réside la signification universelle du Surréalisme, à savoir qu'après cette

\footnotetext{
'Allusion au livre de Hugo Ball : Die Flucht aus der Zeit.

'En opposition à l'abstractivisme qui, au contraire, borne intentionnellement ses possibilités aux actions réciproques et purement esthéthiques de couleurs, surlaces, volumes, lignes, espace, etc. Apparemment pour aider la vieille croyance dans la création à se remettre sur pied, comme le prouve le nom même du groupe: "Abstraction, création".
} 
découverte aucune région de la vie ne peut lui rester fermée. C'est ainsi que la sculpture qui gardait vis-à-vis de tout automatisme une attitude visiblement farouche, devait elle aussi accéder au Surréalisme. À côté des sculptures de Hans Arp et de Giacometti présentées dans cette exposition, il faut mentionner les objets surréalistes "à fonctionnement symbolique" (par exemple La Boule suspendue de Giacometti) et les projets utopiques dont la description suivante peut donner une idée au lecteur : "De grandes automobiles, trois fois plus grandes que nature, seront reproduites (avec une minutie de détails surpassant celle des moulages les plus exacts) en plâtre ou en onyx, pour être enfermées, enveloppées de linge de femme, dans les sépultures, dont l'emplacement ne sera reconnaissable que par la présence d'une mince horloge de paille" (Salvador Dali).

Déjà des œuvres plastiques existantes peuvent fonctionner, dans l'expérimentation surréaliste, comme toute autre "réalité", en tant qu'éléments poétiques, ainsi que l'ont montré les recherches collectives en vue d'un embellissement irrationnel de Paris: "Les plus conventionnelles des statues embelliraient merveilleusement les campagnes. Quelques femmes nues en marbre seraient du meilleur effet sur une grande plaine labourée. Des animaux dans les ruisseaux et des conciles de graves personnages cravatés de noir dans les rivières formeraient de charmants écueils à la monotonie des flots. Le flanc des montagnes s'agrémenterait à ravir de toutes les pétrifications de la danse. Et pour faire la part de la mutilation indispensable, que de têtes sur le sol, que de mains sur les arbres, que de pieds sur le chaume !" (Paul Éluard).

Qu'est-ce que le Surréalisme? Si l'on attend une définition qui réponde à cette question, on restera déçu aussi longtemps que durera ce mouvement. Mon trop bref exposé n'était destiné qu'à déjouer dans une certaine mesure la confusion des idées à propos du Surréalisme, laquelle se répand et s'est fortement introduite dans une partie de l'opinion. Au reste, je ne peux ici que renvoyer aux deux ouvrages d'André Breton: Manifestes du Surréalisme et Les Vases 
communicants. Que l'on ait décelé, dans les démarches successives des surréalistes, des contradictions, et qu'il s'en présente encore, indique que le mouvement est dans la voie la meilleure. Étant donné qu'il a bouleversé du tout au tout les rapports des "réalités", il ne pouvait que contribuer à accélérer la crise générale de conscience et de connaissance de soi qui se fait sentir aujourd'hui.

Max Ernst 